\title{
Tumour $T_{1}$ changes in vivo are highly predictive of response to chemotherapy and reflect the number of viable tumour cells - a preclinical MR study in mice
}

Claudia Weidensteiner ${ }^{1,2,3^{*}}$, Peter R Allegrini ${ }^{2}$, Melanie Sticker-Jantscheff ${ }^{1}$, Vincent Romanet ${ }^{1}$, Stephane Ferretti ${ }^{1}$ and Paul MJ McSheehy ${ }^{1}$

\begin{abstract}
Background: Effective chemotherapy rapidly reduces the spin-lattice relaxation of water protons $\left(T_{1}\right)$ in solid tumours and this change $\left(\Delta T_{1}\right)$ often precedes and strongly correlates with the eventual change in tumour volume (TVol). To understand the biological nature of $\Delta T_{1}$, we have performed studies in vivo and ex vivo with the allosteric mTOR inhibitor, everolimus.

Methods: Mice bearing RIF-1 tumours were studied by magnetic resonance imaging (MRI) to determine TVol and $T_{1}$, and MR spectroscopy (MRS) to determine levels of the proliferation marker choline and levels of lipid apoptosis markers, prior to and 5 days (endpoint) after daily treatment with vehicle or everolimus $(10 \mathrm{mg} / \mathrm{kg}$ ). At the endpoint, tumours were ablated and an entire section analysed for cellular and necrotic quantification and staining for the proliferation antigen Ki67 and cleaved-caspase-3 as a measure of apoptosis. The number of blood-vessels (BV) was evaluated by CD31 staining. Mice bearing B16/BL6 melanoma tumours were studied by MRI to determine $T_{1}$ under similar everolimus treatment. At the endpoint, cell bioluminescence of the tumours was measured ex vivo.

Results: Everolimus blocked RIF-1 tumour growth and significantly reduced tumour $\mathrm{T}_{1}$ and total choline (Cho) levels, and increased polyunsaturated fatty-acids which are markers of apoptosis. Immunohistochemistry showed that everolimus reduced the \%Ki6 ${ }^{+}$cells but did not affect caspase-3 apoptosis, necrosis, BV-number or cell density. The change in $T_{1}\left(\Delta T_{1}\right)$ correlated strongly with the changes in TVol and Cho and \%Ki67 $7^{+}$. In B16/BL6 tumours, everolimus also decreased $T_{1}$ and this correlated with cell bioluminescence; another marker of cell viability. Receiver-operating-characteristic curves $(\mathrm{ROC})$ for everolimus on RIF-1 tumours showed that $\Delta \mathrm{T}_{1}$ had very high levels of sensitivity and specificity $\left(R O C_{A \cup C}=0.84\right)$ and this was confirmed for the cytotoxic patupilone in the same tumour model $\left(\mathrm{ROC}_{\mathrm{AUC}}=0.97\right)$.

Conclusion: These studies suggest that $\Delta T_{1}$ is not a measure of cell density but reflects the decreased number of remaining viable and proliferating tumour cells due to perhaps cell and tissue destruction releasing proteins and/or metals that cause $T_{1}$ relaxation. $\Delta T_{1}$ is a highly sensitive and specific predictor of response. This MRI method provides the opportunity to stratify a patient population during tumour therapy in the clinic.
\end{abstract}

Keywords: Biomarkers, MRI, MRS, T1, Animal models, Everolimus, Tumour

\footnotetext{
* Correspondence: claudia.weidensteiner@uniklinik-freiburg.de

'Oncology Research, Novartis Institutes for Biomedical Research, Basel,

Switzerland

${ }^{2}$ Global Imaging Group, Novartis Institutes for Biomedical Research, Basel,

Switzerland

Full list of author information is available at the end of the article
} 


\section{Background}

Biomarkers are crucial to the development of new drugs and optimization of the existing options, by facilitating selection of the population to treat, confirming proof-ofconcept and acting as early markers of tumour-response. The latter can be provided in the clinic by non-invasive functional imaging, for example positron emission tomography (PET) measurements of $2^{\prime}$-deoxy-2'-[18 F] fluoro-glucose (FDG) and 3'-deoxy-3'-[18 F]fluorothymidine (FLT), dynamic contrast-enhanced magnetic resonance imaging for vascular parameters and diffusionweighted imaging for apoptosis [1,2]. However, they are not always easy to implement, and furthermore may be inappropriate for the mechanism-of-action (MoA) of a particular drug and cannot always detect true responses to the treatment [3-6]. We have recently described a rapid, robust MRI-method, which detects the response of solid tumours to drugs with different MoA in several different experimental models [7]. The method quantifies the spinlattice relaxation of protons $\left(T_{1}\right)$ in tumours both rapidly and accurately using an IR-TrueFISP method. Across several models, the fractional change in tumour $T_{1}\left(\Delta T_{1}\right)$ correlated with the percentage of cells positive for the antigen Ki67 (a marker of cycling cells), but not with other markers such as apoptosis, necrosis or blood volume, all of which showed no consistent change with drugtreatment [7]. Recently, a preclinical study in a neuroblastoma mouse model treated with three different drugs showed a consistent decrease in $\mathrm{T}_{1}$ [8], and a clinical study reported a small decrease in $\mathrm{T}_{1}$ in patients with colorectal cancer metastasis undergoing bevacizumab therapy [9].

To investigate further what $\Delta \mathrm{T}_{1}$ reflects about the tumour biology, we have compared $\Delta \mathrm{T}_{1}$ with magnetic resonance spectroscopy (MRS) markers of proliferation and apoptosis in vivo [10], as well as histology and immunohistochemistry ex vivo following treatment with the allosteric mTOR inhibitor, everolimus (Afinitor) in two different murine tumour models, RIF-1 and B16/BL6. Everolimus was selected for these studies because although the drug has significant clinical activity in several different types of cancer, there is currently no confirmed molecular marker that can stratify the patient population [11]. Using the RIF-1 model, we demonstrate that $\Delta \mathrm{T}_{1}$ is a highly sensitive and specific predictor of response to everolimus and also the microtubule stabilizer patupilone. Collectively, these data further suggest that incorporation of $\mathrm{T}_{1}$ measurements in clinical trials should be an important aid to drug development and optimization of existing drugs.

\section{Methods}

\section{Tumour Models}

All animal experiments were carried-out strictly according to the local Swiss animal welfare regulations. The protocol was approved by the local veterinary authorities (Kantonales Veterinäramt Basel-Stadt, permit number 1974). $\mathrm{C} 3 \mathrm{H} / \mathrm{He}$ female mice (20-25 g) and C57/BL6 mice (20 g) were obtained from Charles River (France) and were acclimatized to local conditions for at least one week prior to experiments. Three experiments were performed in the RIF-1 fibrosarcoma model in $\mathrm{C} 3 \mathrm{H} / \mathrm{He}$ mice, one experiment was performed in the B16/BL6 melanoma model in C57/BL6 mice. All animal experiments were performed under isoflurane anesthesia, and every effort was made to minimize suffering.

Tumour volume (TVol) and animal body-weight (BW) measurements were made at least twice per week including just before treatment (baseline) and the endpoint. TVol was determined using calipers to measure three orthogonal dimensions and applying the formula: $1 " \mathrm{~h}^{*} \mathrm{w}^{*} \pi / 6$.

\section{Murine RIF-1 fibrosarcoma}

Freshly cultured RIF-1 tumour cells were injected subcutaneously $\left(5 \times 10^{6}\right.$ in $50 \mu \mathrm{L}$ phosphate-buffered saline) in the upper thigh of anesthetized $\mathrm{C} 3 \mathrm{H} / \mathrm{He}$ mice, as previously described [12]. After 2 weeks, tumours were of sufficient size (at least $200 \mathrm{~mm}^{3}$ ) for the studies and were divided into two equal groups and treated daily with compound or vehicle. Experiment 1: treatment with everolimus $(n=7)$ compared to vehicle $(n=7)$, experiment 2: treatment with everolimus $(n=8)$ compared to vehicle $(n=8)$, experiment 3 , previously published in [7]: three different doses of patupilone (each group $n=8$ ) compared to vehicle $(n=8)$.

\section{Murine B16/BL6 melanoma}

Freshly cultured B16/BL6 tumour cells expressing the enzyme luciferase were injected intra-dermally $\left(5 \times 10^{4}\right.$ in $1 \mu \mathrm{l})$ into the dorsal pinna of both ears of anesthetized C57/BL6 mice as previously described [12,13]. These black melanoma cells rapidly metastasize from the primary ear tumour to the regional lymph-nodes, in particular the neck. After 2 weeks, mice were divided into two equal groups $(n=10)$ and treated daily with everolimus $(10 \mathrm{mg} / \mathrm{kg}$ p.o.) or vehicle for 6 days (experiment 4). MRI was performed on the metastasis in the cervical lymph nodes on day 5. In one mouse in the vehicle group there was no measurable lymph node metastasis.

\section{Compounds/drugs and their application}

All compounds utilized in this study were obtained from the Novartis chemical department. The compounds and their respective vehicles were prepared each day just prior to administration to animals and the administration volume individually adjusted based upon animal body weight. Everolimus (RAD001) was obtained as a microemulsion and was freshly diluted in a vehicle of $5 \%$ glucose and administered by oral gavage (p.o.) to mice 
daily in a volume of $10 \mathrm{ml} / \mathrm{kg}$ at $10 \mathrm{mg} / \mathrm{kg}$. Patupilone (epothilone B, EPO906) was dissolved in polyethylene glycol-300 (PEG-300) and then diluted with physiological saline $(0.9 \% \mathrm{w} / \mathrm{v} \mathrm{NaCl})$ to obtain a mixture of $30 \%(\mathrm{v} / \mathrm{v})$ PEG-300 and 70\% (v/v) 0.9\% saline. Treatment with vehicle (PEG-300/saline) or patupilone (3, 5 or $6 \mathrm{mg} / \mathrm{kg}$ ) was once weekly using an i.v. bolus of $2-3 \mathrm{sec}$ in the tail vein.

\section{Experimental design}

Mice were divided into different treatment groups so that each group had the same mean TVol, and magnetic resonance (MR) measurements were made before treatment (baseline) i.e. day 0 and at the endpoint. For everolimus, the endpoint was day 5 , and for patupilone it was day $7 . T_{1}$ was measured in all four experiments. MRS was performed in experiment 1 only. Bioluminescence was measured ex vivo in experiment 4 (see below). At the end of everolimus-experiment 1, animals were sacrificed by $\mathrm{CO}_{2}$ inhalation, the tumours ablated and prepared for histology and immunohistochemistry (IHC) as previously described [7].

\section{Magnetic Resonance in vivo}

Animals were anaesthetised using 1.5\% isoflurane (Abbott, Cham, Switzerland) in a 1:1 mixture of $\mathrm{O}_{2} / \mathrm{N}_{2}$ and placed on an electrically warmed pad for canulation of one lateral tail-vein as previously described [7]. MRI experiments were performed on a Bruker DBX 47/30 or Avance 2 spectrometer (Bruker Biospin, Ettlingen, Germany) at $4.7 \mathrm{~T}$ equipped with a self-shielded $12 \mathrm{~cm}$ bore gradient system.

\section{Quantitative $T_{1}$ imaging}

The spin-lattice relaxation of protons $\left(T_{1}\right)$ was measured with an inversion recovery (IR) TrueFISP (true fast imaging with steady state precession sequence, [14]) imaging sequence as previously described [7]. The basic sequence was a series of 16 TrueFISP images acquired at a time interval, TI, following a global $180^{\circ}$ inversion pulse ( $\mathrm{TI}=210 \mathrm{~ms}$ to $5960 \mathrm{~ms}$ in $324 \mathrm{~ms}$ increments). Each TrueFISP image (one slice containing the central part of the tumour) was acquired with a flip angle $\alpha$ of $30^{\circ}$, a matrix size of $128 \times 96$, a field-of-view of $30 \times 22.5 \mathrm{~mm}^{2}$, a slice thickness of $2 \mathrm{~mm}$, an echo time (TE) of $1.7 \mathrm{~ms}$, and a repetition time (TR) of $3.4 \mathrm{~ms}$. Pixelwise $\mathrm{T}_{1}$ calculation was done using the method described in [15]. A region of interest (ROI) comprising the entire tumor was drawn manually on the resulting $\mathrm{T}_{1}$ map and the mean $\mathrm{T}_{1}$ of the central tumour slice was calculated in this ROI. MR image analysis was performed off-line with in-house written software based on IDL 6.0 programming environment (Research Systems Inc., Boulder, CO, USA).

\section{${ }^{1} \mathrm{H}$-MR spectroscopy}

Localized shimming with FASTMAP method was performed on a $2.5 \mathrm{~mm}^{3}$ voxel to obtain line widths of $<20 \mathrm{~Hz}$. Point resolved spectroscopy (PRESS) experiments at the same voxel position (voxel size $=8 \mathrm{~mm}^{3}, \mathrm{TE}=$ $20 \mathrm{msec}, \mathrm{TR}=1500 \mathrm{msec}, \mathrm{SW}=4000 \mathrm{~Hz}, \mathrm{TD}=2048$, with external volume suppression) were performed. One spectrum was acquired with water suppression (400 averages) and one spectrum without water suppression (1 average). The total time for MRS was 10-12 min for each mouse. The water signal (one peak) of the nonsuppressed spectrum was used as an internal reference for relative quantification of metabolites using the metabolite to $\mathrm{H}_{2} \mathrm{O}$ ratio $\left(\mathrm{Cho} / \mathrm{H}_{2} \mathrm{O}\right.$ for choline, etc.). Peaks in the water-suppressed spectrum were identified by their chemical shifts, so total choline (Cho) was at $3.2 \mathrm{ppm}$, $\mathrm{CH}_{3}$-lipids at $0.9 \mathrm{ppm}, \mathrm{CH}_{2}$-lipids at $1.3 \mathrm{ppm}$, creatine at $3.0 \mathrm{ppm}$, and polyunsaturated fatty-acids (PUFA) at $5.3 \mathrm{ppm}$ and very weakly at $2.8 \mathrm{ppm}$; however the latter peak was not used for any calculations.

\section{Histology and immunohistochemistry}

A tumour slice of 3-4 mm thickness was cut from the largest circumference of the tumour, immersion-fixed in $4 \%(\mathrm{w} / \mathrm{v})$ phosphate-buffered formalin ( $\mathrm{pH}$ 7.4; J.T. Baker, Medite, Service AG, Dietikon, Switzerland) at $4^{\circ} \mathrm{C}$ for 24 hours and processed into paraffin as previously described [4]. IHC was performed on paraffin sections of $3 \mu \mathrm{m}$ using the following antibodies for detection of (i) cleaved Caspase-3 (rabbit polyclonal antibody \#9661, Cell Signaling, Danvers, MA, USA) (ii) Ki67 (rat monoclonal antibody, clone TEC3, \#M7249, DAKO, Glostrup, Denmark) and (iii) CD31 (rabbit polyclonal antibody, \#E11114, Spring Biosciences, Pleasanton, CA, USA).

\section{Image acquisition and analysis of histological slices}

For quantification, the entire section was scanned using the MiraxScan system (Carl Zeiss AG, Jena, Germany). The absolute size of viable, necrotic and complete tissue areas was measured on the full scans using MiraxViewer software (Carl Zeiss AG, Jena, Germany). Quantification of Ki67 positive and negative nuclei in the complete viable areas was performed in a fully automated manner with TissueMap software at Definiens AG, Munich, Germany. Results were summarized as the total area, percentage-viable and percentage-necrotic area, total number of nuclei and the cell density (number of nuclei per $\mathrm{mm}^{2}$ ) in both the viable and total (including therefore necrotic) areas. Cleaved caspase- 3 positive particles were quantified as positive pixels per total pixels in a semi-automated fashion with the AnalySIS ${ }^{\circ}$ FIVE software (OlympusSIS, Münster, Germany) on six images (346.7 $\times 260 \mu \mathrm{m}^{2}$ each) per section excluding necrotic areas and border zones of necrotic areas. CD31 stained 
slides were scanned with the Aperio ScanScopeXT slide scanner (Aperio, Vista, CA, USA) and vessels were quantified with the Aperio ImageScope software, using the Microvessel Analysis v1 Algorithm.

\section{Bioluminescence}

Because of the black pigmentation of the C57/BL6 mice, bioluminescence (BioL) could not adequately be measured in vivo and therefore was determined ex vivo as follows. After 6 days, the cervical lymph-nodes were removed and weighed and then iced. Individual lymph-nodes were homogenized at $4^{\circ} \mathrm{C}$ with $1 \mathrm{~mL}$ cold phosphate-buffered saline (without $\mathrm{Ca}^{2+}$ and $\mathrm{Mg}^{2+}$ ), rinsed in the same buffer, and $200 \mu \mathrm{l}$ triplicates placed in a 96-well plate with $50 \mu \mathrm{l}$ D-luciferin $(1 \mathrm{mg} / \mathrm{mL})$. BioL was measured at an emission wavelength of $560 \mathrm{~nm}$ using the imaging chamber of the IVIS $^{\mathrm{TM}}$ system (Caliper Life Sciences Inc, Hopkinton, MA, USA) for $1 \mathrm{~min}$ at room temperature.

\section{Data analysis}

Results are presented as mean \pm SEM except where stated and all available data are shown. The $\mathrm{T} / \mathrm{C}$ ratio is commonly used to quantify tumour growth inhibition, where $\mathrm{T}$ and $\mathrm{C}$ represent the means of the relative tumour volumes (tumour volume divided by its initial volume) of the treatment and control mice, respectively [16]. Longitudinal changes, such as in tumour volume $(\triangle \mathrm{TVol})$ or in $\mathrm{T}_{1}\left(\Delta \mathrm{T}_{1}\right)$, were expressed as change between endpoint and baseline divided by value at baseline (fractional change in $\%)$. The $\mathrm{T} / \mathrm{C}$ ratio was calculated for all parameters. For parameters measured at one time point only (such as histological read-outs), $\mathrm{T} / \mathrm{C}$ was calculated as ratio of means of treatment and control mice, respectively. Differences between groups were analysed using a 2-tailed t-test. For the in vivo biomarker analyses which involved longitudinal analyses in the same animals, differences were analysed by a) 2-way repeated measures ANOVA and b) t-test at the endpoint; the latter method is therefore associated with the respective $\mathrm{T} / \mathrm{C}$. The different dose groups in experiment 3 were tested with 1-way ANOVA vs. control group. Quantification of the linear-relationship between the various parameters measured in vivo and ex vivo were analysed by Pearson's correlation to provide the correlation coefficient $(r)$ and the significance (p). Application of the non-parametric Spearman's correlation did not affect the results except in one case (see Results). To facilitate comparison of PUFA levels which were not always detectable, a 2-sided Fisher's exact test was also used. For all tests, the level of significance was set at $\mathrm{p}<0.05$ (two-tailed) where ${ }^{*} \mathrm{p}<0.05,{ }^{* *} \mathrm{p}<0.01,{ }^{* * *} \mathrm{p}<0.001$ versus vehicle.

To determine the sensitivity and specificity of a change in the imaging marker $T_{1}$ as a marker of tumour response to treatment, receiver-operator curves (ROC) were generated
$[17,18]$ using Graphpad Prism (GraphPad Software, La Jolla, CA, USA) considering mice treated with the drugs everolimus (experiment 1 and 2) or patupilone (experiment 3). Briefly, responders (R) to drug-treatment were defined as showing no change or regression, in TVol, defined as $\triangle \mathrm{TVol} \leq 10 \%$, while all others were considered non-responders (NR). Each of these tumours was then classified as $R$ or $N R$ by the $\Delta T_{1}$ at different discrete cut-offs to generate at each $\Delta \mathrm{T}_{1}$ value a table of positive and negative predictions for determination of specificity and sensitivity at each value. The plot of 1specificity versus sensitivity generated the ROC curve and the area under this curve (AUC) was quantified by the trapezoidal method.

\section{Results}

Effects of everolimus on MRI and MRS biomarkers in RIF-1 tumours in vivo

Murine RIF-1 tumours grew rapidly having a 2.5-fold increase in tumour volume after just 5 days, but daily treatment with everolimus (10 $\mathrm{mg} / \mathrm{kg}$ p.o.) strongly inhibited tumour growth causing essentially stable disease at the 5 day endpoint with a T/C of 0.05 (Table 1). Both groups had a significant difference in TVol at baseline (slightly larger TVol in the treatment group), but this did not have an effect on the results, as can be seen in Table 1. Quantification of tumour $\mathrm{T}_{1}$ by MRI at baseline gave a mean \pm SD of $2301 \pm 100 \mathrm{msec}$ (both groups, $\mathrm{n}=14$ ) which showed no significant change in vehicletreated mice, but was reduced in $7 / 7$ mice treated with everolimus providing a small but highly significant mean decrease of $10 \pm 2 \%$ after 5 days treatment (Figure 1, Table 1).

${ }^{1} \mathrm{H}$-MRS on the same tumours at the same time-points was also performed to provide signals for total choline, creatine, as well as polyunsaturated lipids (PUFA) and saturated $\left(\mathrm{CH}_{2}\right.$ and $\left.\mathrm{CH}_{3}\right)$ lipids (Figure $\left.2 \mathrm{~A}\right)$. The strong water signal (unsuppressed) was used to provide quantitative information as ratios (see Methods). This data showed that creatine and saturated lipids did not change in either treated-group (Table 1). However, total choline (Cho) in most cases (5/7) decreased in everolimustreated tumours, with a mean change in choline $\triangle \mathrm{Cho} /$ $\mathrm{H}_{2} \mathrm{O}$ of $27 \pm 15 \%$ (statistically significant only in ANOVA, not in t-test; Figure 2B,C). The PUFA peaks were broad and of low intensity (Figure 2A) and were only detectable at baseline in 1/7 tumours for each group. However, after 5 days treatment they were more prevalent, permitting quantification in $2 / 7$ vehicle-treated and 5/7 everolimustreated tumours which showed a T/C of 2.2 (Table 1 ). This data was obviously rather variable and scarce due to the limit-of-detection by MRS and there was no significant difference between the two groups although a two-way repeated-measures ANOVA (as used for $\mathrm{T}_{1}$ and Cho) 
Table 1 Summary of RIF-1 measurements in vivo and ex vivo

\begin{tabular}{|c|c|c|c|c|c|}
\hline \multirow[t]{2}{*}{ Parameter } & \multicolumn{2}{|c|}{ Vehicle } & \multicolumn{2}{|c|}{ Everolimus } & \multirow[t]{2}{*}{$\mathrm{T} / \mathrm{C}$} \\
\hline & Day 0 & Day 5 & Day 0 & Day 5 & \\
\hline TVol $\left(\mathrm{mm}^{3}\right)$ & $447 \pm 75$ & $1118 \pm 150$ & $706 \pm 85$ & $736 \pm 100$ & $0.05^{* * *}$ \\
\hline $\mathrm{T}_{1}$ (msec) & $2266 \pm 46$ & $2265 \pm 30$ & $2335 \pm 23$ & $2090 \pm 45$ & $0.89 * *$ \\
\hline choline/ $/ \mathrm{H}_{2} \mathrm{O}$ [a.u.] & $2.72 \pm 0.18$ & $2.72 \pm 0.2$ & $2.6 \pm 0.12$ & $1.82 \pm 0.32$ & 0.73 \\
\hline $\mathrm{CH}_{2} / \mathrm{H}_{2} \mathrm{O}$ [a.u.] & $6.44 \pm 0.85$ & $7.3 \pm 1.17$ & $6.89 \pm 0.35$ & $11.0 \pm 1.5$ & 1.3 \\
\hline $\mathrm{CH}_{3} / \mathrm{H}_{2} \mathrm{O}$ [a.u.] & $2.56 \pm 0.43$ & $2.86 \pm 1.74$ & $3.06 \pm 0.34$ & $4.87 \pm 0.72$ & 1.2 \\
\hline PUFA/ $\mathrm{H}_{2} \mathrm{O}$ [a.u.] & $0.1 \pm 0.1$ & $0.37 \pm 0.24$ & $0.25 \pm 0.25$ & $0.8 \pm 0.39$ & 2.2 \\
\hline creatine $/ \mathrm{H}_{2} \mathrm{O}$ [a.u.] & $1.27 \pm 0.15$ & $1.14 \pm 0.05$ & $1.07 \pm 0.06$ & $0.89 \pm 0.09$ & 0.9 \\
\hline total area $\left(\mathrm{mm}^{2}\right)$ & - & $65.8 \pm 10.0$ & - & $43.6 \pm 5.6$ & 0.66 \\
\hline viable area $\left(\mathrm{mm}^{2}\right)$ & - & $52.1 \pm 9.4$ & - & $33.1 \pm 4.7$ & 0.64 \\
\hline \%necrosis & - & $21.5 \pm 6.1$ & - & $24.9 \pm 3.3$ & 1.16 \\
\hline total cells (thousand) & - & $489 \pm 82$ & - & $328 \pm 48$ & 0.67 \\
\hline cells/viable mm² & - & $9671 \pm 454$ & - & $9923 \pm 562$ & 1.03 \\
\hline$\% \mathrm{Csp}^{+}$area & - & $0.39 \pm 0.07$ & - & $0.27 \pm 0.02$ & 0.7 \\
\hline $\mathrm{BV}$ per $\mathrm{mm}^{2}$ & - & $728 \pm 159$ & - & $768 \pm 37$ & 1.06 \\
\hline$\% \mathrm{Ki} 67^{+}$cells & - & $44.6 \pm 2.5$ & - & $26.5 \pm 1.0$ & $0.59^{* * *}$ \\
\hline $\mathrm{Ki} 67^{+}$cells $/ \mathrm{mm}^{2}$ & - & $4274 \pm 205$ & - & $2614 \pm 141$ & $0.61^{* * *}$ \\
\hline Ki67 cells/mm² & - & $5396 \pm 457$ & - & $7309 \pm 462$ & $1.35^{*}$ \\
\hline
\end{tabular}

$\mathrm{C} 3 \mathrm{H}$ mice bearing RIF-1 tumours were treated with everolimus ( $10 \mathrm{mg} / \mathrm{kg} / \mathrm{day}, \mathrm{n}=7)$ or vehicle $(\mathrm{n}=7)$ for 5 days prior to sacrifice. Tumour volume, $\mathrm{T}_{1}$ and the various MRS parameters were quantified prior to treatment (day 0 ) and after 5 days treatment. Animals were then culled and the tumours ablated and prepared for immunohistochemistry as described in Methods. After immunostaining for Ki67 and cleaved caspase-3, the entire tumour sections were scanned to provide viable and necrotic areas in $\mathrm{mm}^{2}$. The number of cells and the number and percentage staining for Ki67 and caspase-3 is shown only for the viable area but essentially identical results were obtained if the entire area was used. Blood vessels (BV) were quantified from CD31 stained slices. All results show the mean \pm SEM for each tumour, significant changes are indicated by emboldened numbers where ${ }^{*} \mathrm{p}<0.05,{ }^{* *} \mathrm{p}<0.01,{ }^{* * *} \mathrm{p}<0.001$ comparing the two treatment group means (2-tailed t-test).

A

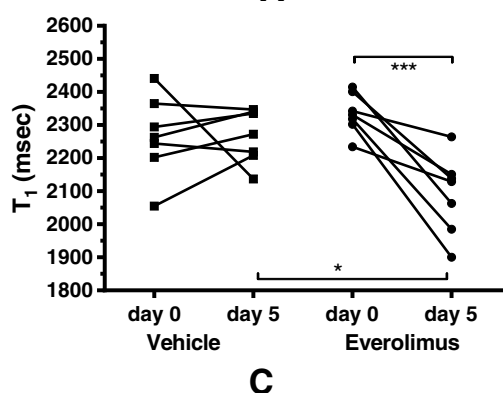

C

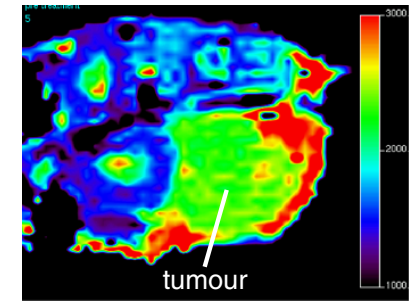

day 0

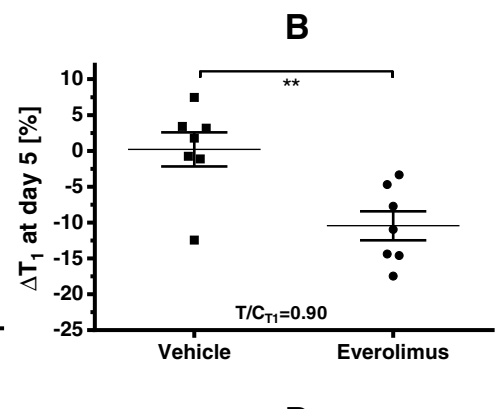

D

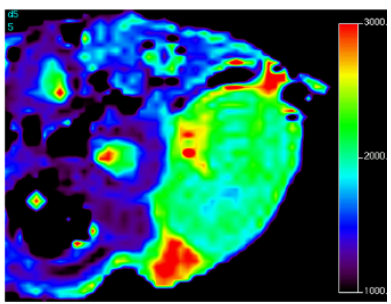

day 5

Figure 1 Everolimus decreases the $\mathrm{T}_{1}$ of RIF-1 tumours. C3H mice bearing RIF-1 tumours were treated with everolimus (10 mg/kg/day) or vehicle for 5 days and the spin-lattice relaxation of protons $\left(T_{1}\right)$ in tumours was measured on day 0 and at the endpoint day 5 . Results show the individual values for each tumour, $n=7$ per treatment group $(\mathbf{A})$ and the mean \pm SEM fractional change $\Delta T_{1}$ for each treatment $(\mathbf{B})$, where ${ }^{*} p<0.05,{ }^{* *} p<0.01,{ }^{* * *} p<0.001$ as shown. Panel C \& D show an MRI-derived $T_{1}$ map from a representative RIF-1 tumour (arrow) before (C) and after (D) treatment with everolimus. 

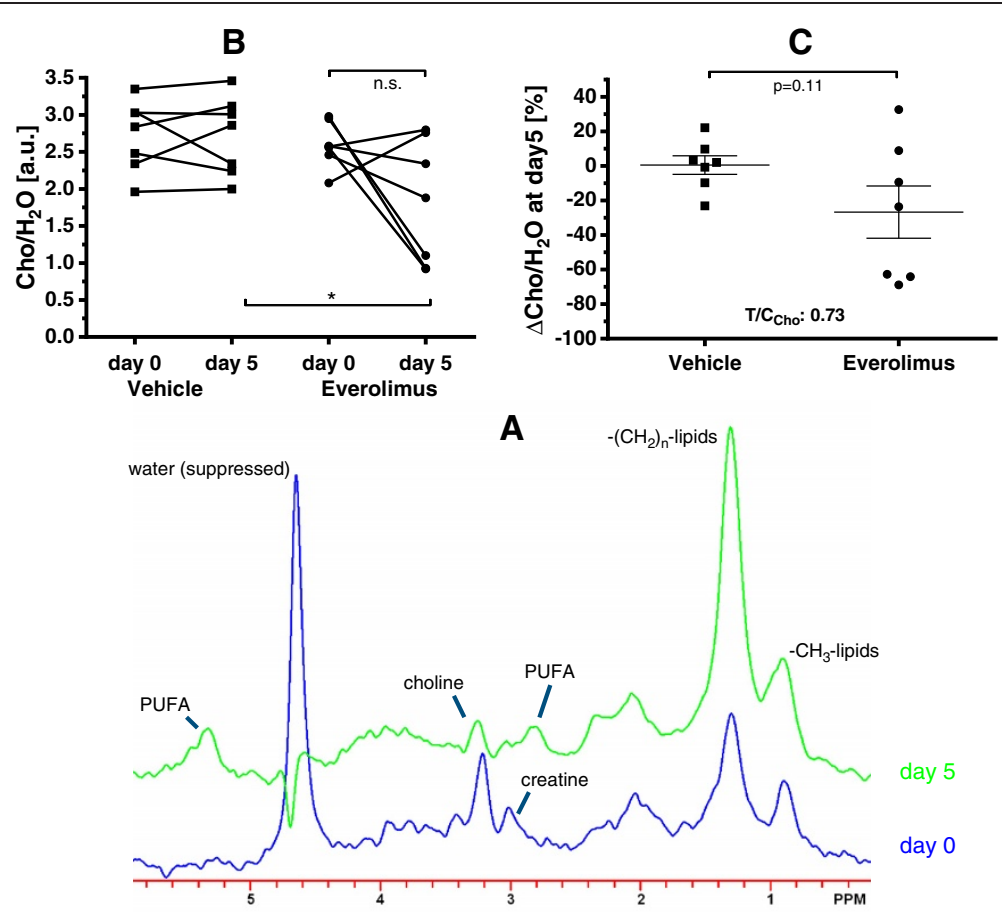

Figure 2 Everolimus decreases the $\mathrm{Cho} / \mathrm{H}_{2} \mathrm{O}$ ratio of RIF-1 tumours. $\mathrm{C} 3 \mathrm{H}$ mice bearing RIF-1 tumours were treated with everolimus (10 mg/kg/day) or vehicle for 5 days and the ratio of total choline to (unsuppressed) water $\left(\mathrm{Cho} / \mathrm{H}_{2} \mathrm{O}\right)$ in tumours was measured on day 0 and at the endpoint day 5. Panel A shows a ${ }^{1} \mathrm{H}$-MRS spectrum from a representative RIF-1 tumour before and after treatment with everolimus. Graphs show the individual values for each tumour, $\mathrm{n}=7$ per treatment group (B) and the mean $\pm \mathrm{SEM}$ fractional change $\triangle \mathrm{Cho} / \mathrm{H}_{2} \mathrm{O}$ for each treatment (C), where ${ }^{*} \mathrm{p}<0.05$ as shown.

showed that everolimus significantly increased PUFA ( $\mathrm{p}=$ 0.007), a parameter that has also been associated with apoptosis [10].

\section{Ex vivo analyses of everolimus on RIF-1 tumours}

At the endpoint, the ablated tumours were prepared for histology. Since everolimus inhibited tumour growth, there was of course a reduction in the total and viable area and consequently a reduction in the total cell number examined by IHC comparing everolimus-treated to vehicle-treated mice (Table 1, Figure 3), although these did not quite reach significance $(\mathrm{p}=0.1)$. The cell density (cells per $\mathrm{mm}^{2}$ ) in the viable (or total) area and the \%-necrosis was the same in each group (Table 1). The number of cells positive for the proliferation marker Ki67 was relatively high in vehicle-treated mice $(45 \pm 3 \%)$ and everolimus caused a clear and highly significant decrease in the total number and $\% \mathrm{Ki} 7^{+}$cells to $27 \pm 1 \%$ (Table 1 ; Figure 3, first and second row). Correspondingly, there was a significant increase in the number of Ki67 $7^{-}$cells. In contrast, there was a very low level of apoptosis as measured by caspase- 3 staining in these tumours $(<1 \%)$ and this was not affected by everolimus treatment (Table 1; Figure 3, third row). The number of blood-vessels (BV) per slice was rather variable, particularly in the vehiclegroup, and a comparison of the blood-vessel density between treatment groups showed no effect from everolimus (Table 1; Figure 3, last row CD31).

\section{Relationships between RIF-1 biomarkers and tumour response}

As previously observed for several different experimental models and drugs, including everolimus [7], the change in $\mathrm{T}_{1}\left(\Delta \mathrm{T}_{1}\right)$ was highly significantly $(\mathrm{p}=0.0032)$ positively correlated with the change in RIF-1 tumour volume ( $\triangle \mathrm{TVol})$, see Figure $4 \mathrm{~A}$, but there was no significant correlation between $\triangle \mathrm{Cho} / \mathrm{H}_{2} \mathrm{O}$ and $\Delta \mathrm{TVol}$. Correlation of $\Delta \mathrm{T}_{1}$ and $\triangle \mathrm{Cho} / \mathrm{H}_{2} \mathrm{O}$ reached significance $(\mathrm{r}=0.58, \mathrm{p}=0.028)$, see Figure $4 \mathrm{~B}$, although not when a Spearman correlation was applied $(\mathrm{r}=0.43, \mathrm{p}=0.13) . \Delta \mathrm{T}_{1}$ showed a significant positive correlation with the $\% \mathrm{Ki}^{+} 7^{+}$cells (Figure $4 \mathrm{C}$ ), a similar level of correlation existed between $\% \mathrm{Ki} 67^{+}$and $\triangle \mathrm{Cho} / \mathrm{H}_{2} \mathrm{O}$ $(\mathrm{r}=0.56, \mathrm{p}=0.036)$; and of course negative correlation with the $\% \mathrm{Ki67}$ cells (graphs not shown). There was no significant relationship between basal $\mathrm{T}_{1}$ value and $\Delta \mathrm{TVol}$ in keeping with previous observations in many different preclinical models [7] that basal $\mathrm{T}_{1}$ cannot predict response. The final $\mathrm{T}_{1}$ or $\Delta \mathrm{T}_{1}$ was unrelated to cell density, or indeed the total number of cells, with flat lines of correlation and wide scatter (results not shown). Thus, $\Delta \mathrm{T}_{1}$ was unrelated at the endpoint to cell density or the extracellular space but was related to the remaining 


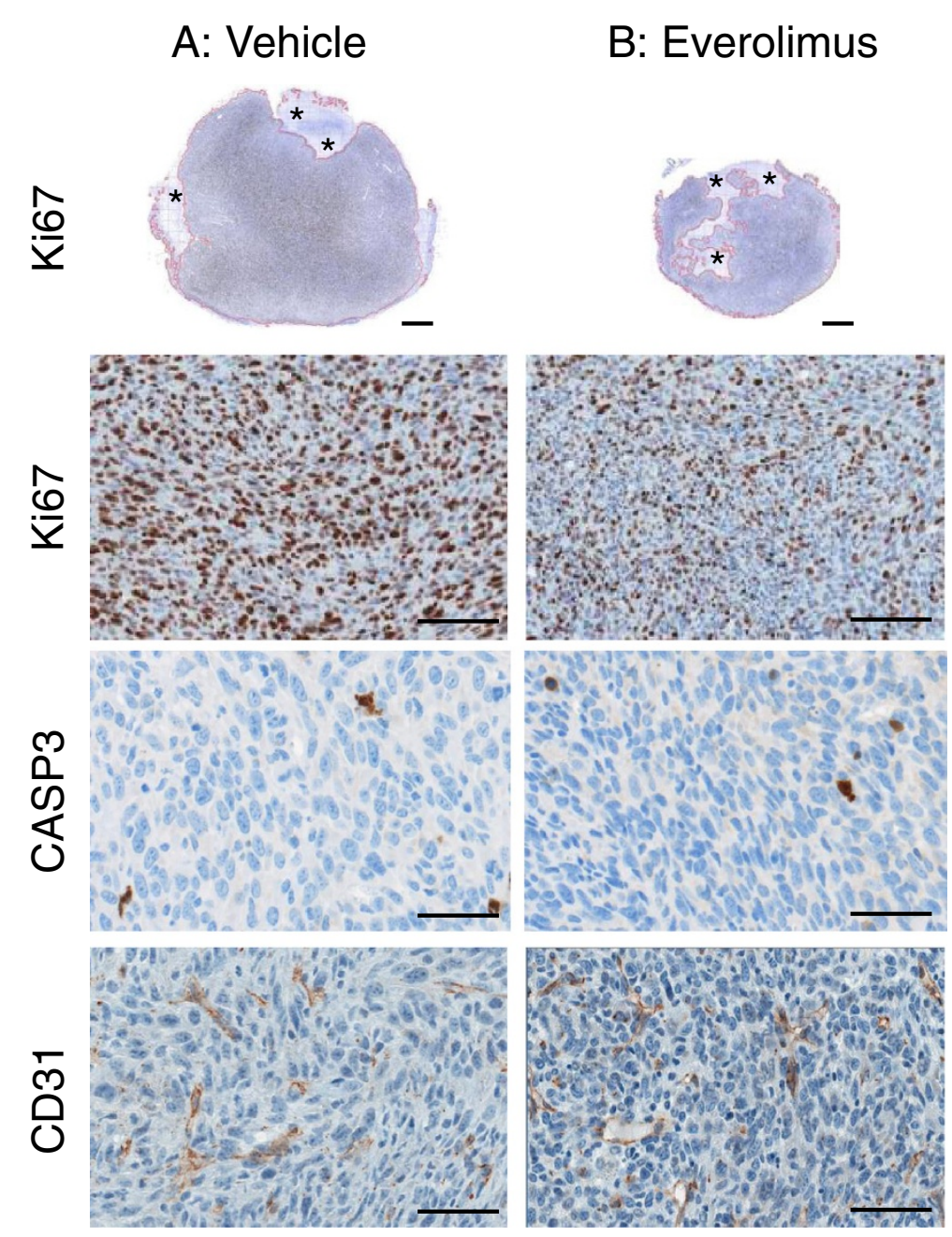

Figure 3 Immunohistochemistry in RIF-1 tumours after everolimus or vehicle treatment. C3H mice bearing RIF-1 tumours were treated with vehicle (A, left column) or everolimus at $10 \mathrm{mg} / \mathrm{kg} /$ day (B, right column) for 5 days prior to sacrifice ( $\mathrm{n}=7$ per group). Tumours were ablated and prepared for immunohistochemistry as described in Methods. The entire sections were scanned. Ki67-stained slices of one representative tumour from each treatment (scalebar $=1 \mathrm{~mm}$ ) are shown in row 1. Viable tumor tissue is outlined in red and necrosis regions are marked with asterisks. Percentage of Ki67-positive cells was $46 \%$ and $26 \%$ and the total tumour area was $43.9 \mathrm{~mm}^{2}$ ( $8 \%$ necrosis) and 22.4 mm ${ }^{2}$ (19\% necrosis) for the vehicle-treated and everolimus-treated mice, respectively. Magnified sections stained for Ki67 (scalebar = 50 um), cleaved caspase-3 (CASP3, scalebar $=25 \mu \mathrm{m})$, and CD31 (scalebar $=25 \mu \mathrm{m})$ are shown below in row 2, 3, and 4, respectively. There was no difference between the groups in apoptosis (CASP-3 staining) and blood-vessel density (CD31 staining).
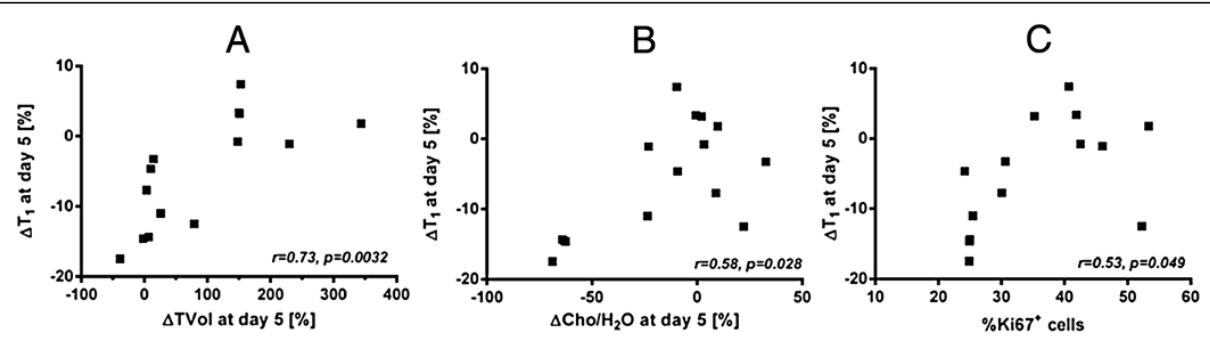

Figure 4 Inter-relationships of biomarkers following everolimus or vehicle treatment of RIF-1 tumours. Graphs A-C show Pearson correlations with the associated $r$ and $p$ values between the fractional change in $T_{1}\left(\Delta T_{1}\right)$ and the fractional change in tumour volume ( $\Delta T$ TVol), the fractional change in total choline $\left(\Delta \mathrm{Cho} / \mathrm{H}_{2} \mathrm{O}\right)$, and percentage of Ki67 positive cells, respectively, after 5 days of everolimus or vehicle treatment ( $n=7$ per group) of $\mathrm{C} 3 \mathrm{H}$ mice bearing RIF-1 tumours. 
number of proliferating cells (and negatively correlated to the number of non-proliferating cells). PUFA levels, which also tended to change with treatment could not be formally correlated since the data was categorical, but a Fisher's exact test showed a significant association between Cho and PUFA ( $\mathrm{p}=0.02)$ i.e. proliferation decreased as apoptosis increased.

\section{Sensitivity and specificity of $\Delta \mathrm{T}_{1}$ as a response biomarker in RIF-1 tumours}

Correlations and linear regression provide indications of whether a biomarker could be used to predict response, but a receiver operating characteristic curve (ROC) can be more definitive in terms of the specificity and sensitivity of the marker. To generate such a curve for everolimus, data from experiments 1 and 2 was pooled from RIF-1 tumours (Figure 5A). The left panel shows the $\triangle T V o l$ for mice treated with vehicle or everolimus and the right panel the $\Delta T_{1}$ in those tumours from day 0 to day 5 ( $n=15$ vehicle, $n=13$ everolimus; in the everolimus group of experiment 2 one mouse died before endpoint and $T_{1}$ measurement failed in another mouse). Responders to everolimus treatment were defined as showing a maximum change in $\triangle \mathrm{TVol}$ of $+10 \%$ (stable disease or regression), so giving $5 \mathrm{R}$ and $8 \mathrm{NR}$ and providing the 'gold-standard'. Each of these 13 tumours was then classified as a $\mathrm{R}$ or NR by the $\Delta \mathrm{T}_{1}$ using different discrete cut-offs ranging from $-16.5 \%$ to $-2.5 \%$ to generate at each $\Delta \mathrm{T}_{1}$ value a table of positive and negative predictions for determination of specificity and sensitivity at each value, see for example Table $2 \mathrm{~A}$. The plot of 1-specificity versus sensitivity generated the ROC curve and the area under this curve (AUC) was quantified giving a value of 0.84 which is considered to be very good predictive ability [17].

The same approach was used to analyse data already published [7] from the cytotoxic patupilone on the same RIF-1 tumour model. In this case, a dose-response was used (Figure 5B, left panel) and $\mathrm{R}$ and NR identified in the same way giving $7 R$ and $13 N R$ (from the 20 tumours). The right panel (Figure $5 \mathrm{~B}$ ) shows the $\Delta \mathrm{T}_{1}$ in those tumours from day 0 to day 7 ( $n=6-8$ per dose). Using once more discrete $\Delta \mathrm{T}_{1}$ values from $-24 \%$ to $8.5 \%$ a table of positive and negative predictions was generated (see for example Table 2B) and the ROC plotted (Figure 5B). The AUC of this plot was 0.97 confirming outstanding predictive ability for $\Delta \mathrm{T}_{1}$ in the RIF-1 model.

\section{Relationship between bioluminescence and $T_{1}$ in B16/BL6 tumours}

Everolimus inhibited growth of B16/BL6 lymph-node metastases after 6 days daily treatment leading to a T/C ratio for the weight of the dissected metastases of $\mathrm{T} /$ $\mathrm{C}_{\text {weight }}=0.60$ and this was associated with a highly significant decrease in the $\mathrm{T}_{1}$ of the metastases of $19 \pm$ $3 \%$ (Figure $6 \mathrm{~A}, \mathrm{~B}$ ). $\mathrm{T}_{1}$ measurement failed in one mouse treated with vehicle and in two mice treated with everolimus resulting in $\mathrm{n}=8 \Delta \mathrm{T}_{1}$ values in each group. Bioluminescence from these lymph-nodes measured ex vivo was also significantly decreased (Figure 6C) and this correlated significantly with the $\Delta T_{1}$ (Figure 6D). Since the enzyme luciferase is only located within the melanoma cells, the bioluminescence should only reflect the viable tumour cells which supports the notion that a change in $\mathrm{T}_{1}$ is an indirect measurement of the viable and/or proliferating cell fraction.

\section{Discussion}

We have previously shown that a small but highly significant decrease in the mean spin-lattice relaxation of protons $\left(\mathrm{T}_{1}\right)$ of experimental tumours induced by various different types of chemotherapy is strongly correlated with the change in tumour volume and also the immunohistochemical proliferation marker Ki67 [7]. Furthermore, in the RIF-1 model the antimetabolite 5FU also decreased levels of the proliferation marker choline and this too was correlated with the change in $T_{1}\left(\Delta T_{1}\right)$. The data presented here on RIF-1 and B16/BL6 tumours confirm these observations for the allosteric mTOR inhibitor everolimus, providing further evidence that $\Delta T_{1}$ reflects the number of remaining proliferating tumour cells following successful chemotherapy. The greater the decrease in $T_{1}$, the lower the percentage of proliferating cells after therapy. In the previous report, a sample area (10\%) of an ex vivo tumour slice was examined histologically, and thus, true cell density and also therefore the overall extracellular space could not be assessed either. In two models, using the cytotoxic patupilone on murine RIF-1 and rat mammary BN472, there were trends for cell-density to decrease by approx. $10 \%$ but neither reached significance [7]. In this report, we have made a detailed histological study of the effect of everolimus on RIF-1 tumours grown s.c. in murine $\mathrm{C} 3 \mathrm{H}$ mice.

RIF-1 cells are sensitive to everolimus with an IC50 in vitro of $2.6 \pm 1.6 \mathrm{nM}$ (insensitive cells have an IC50 > $1 \mu \mathrm{M}$, see references $[19,20])$, but this is still not as sensitive as the endothelial cells which have IC50 $<1 \mathrm{nM}$, which likely explains the fact that everolimus has antitumour cell as well as anti-angiogenic properties [19]. Daily treatment of mice bearing RIF-1 tumours caused tumour stasis, and consistent with this, histology at the endpoint of 5 days showed a decrease in total tumour area and a proportional decrease in the viable area of approx. 35\% compared to vehicle (both not significant, $\mathrm{p}<0.1)$. However, the total number of cells showed a similar trend for a decrease in proportion $(\mathrm{p}<0.1)$ and thus the overall cell density in the viable areas was unchanged. Since necrosis was also not affected by everolimus 
A
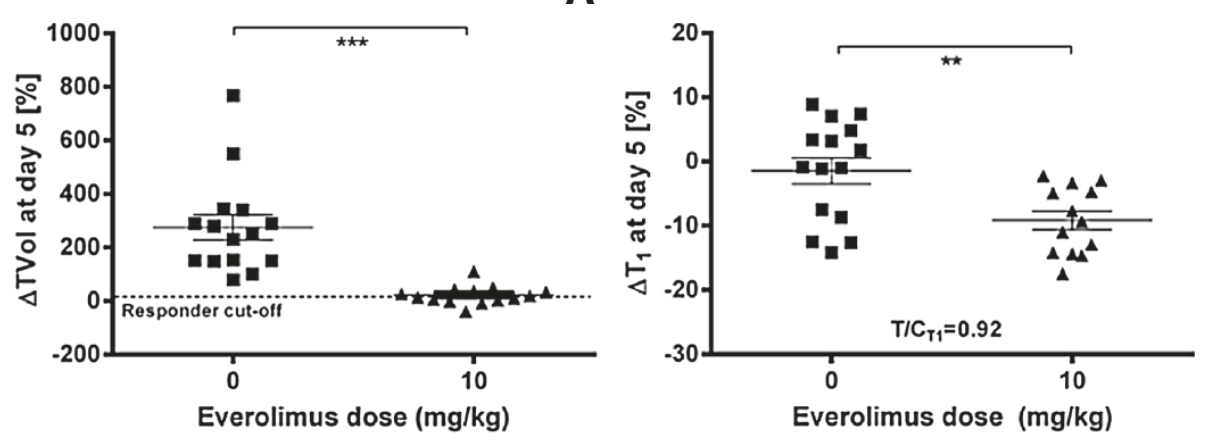

ROC

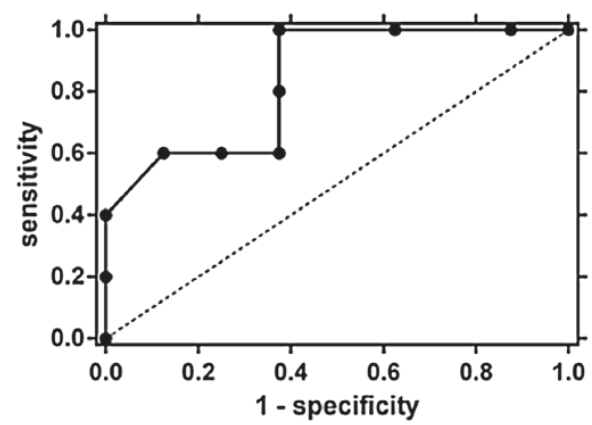

B
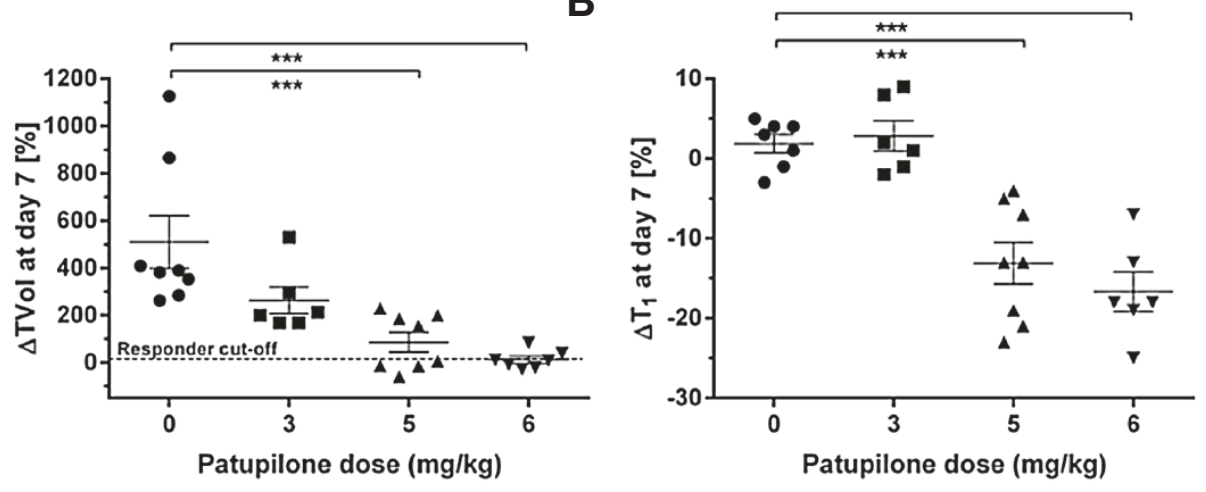

ROC

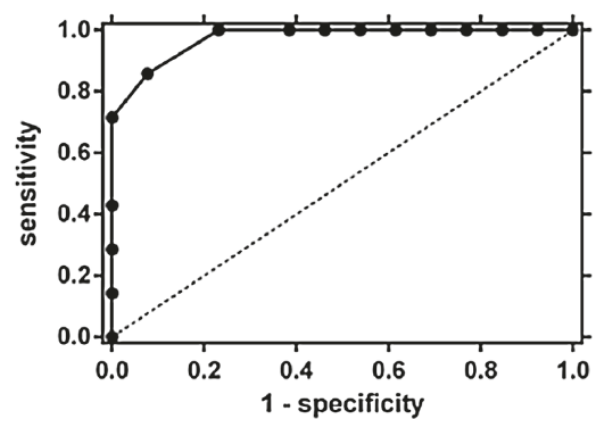

Figure 5 (See legend on next page.) 
(See figure on previous page.)

Figure $\mathbf{5}$ Sensitivity and specificity of $\Delta \mathrm{T}_{\mathbf{1}}$ for everolimus and patupilone chemotherapy in the RIF-1 tumour model. A. C $3 \mathrm{H}$ mice bearing RIF-1 tumours were treated with everolimus ( $10 \mathrm{mg} / \mathrm{kg} /$ day) or vehicle for 5 days and TVol and the spin-lattice relaxation of protons ( $\left.\mathrm{T}_{1}\right)$ in tumours was measured on day 0 and at the endpoint day $5(n=15$ per group on day 0$)$. In the everolimus group, one mouse died before endpoint and $T_{1}$ measurement failed in another mouse on day 5 . Results show the change in TVol ( $\triangle T$ Vol) (left panel) and the fractional change in $T_{1}$ $\left(\Delta T_{1}\right)$ (right panel) for each treatment on day 5 , where ${ }^{* *} p<0.01,{ }^{* * *} p<0.001$ as shown. The ROC plots 1 -specificity versus sensitivity for tumours treated with everolimus only and has an $\mathrm{AUC}=0.84$; the dashed line is the line of equivalence where the $\mathrm{AUC}=0.5$. $\mathbf{B}$. $\mathbf{C} 3 \mathrm{H}$ mice bearing RIF-1 tumours were treated with patupilone $\left(3,5\right.$ or 6 mg/kg i.v. bolus once) or vehicle and TVol and $T_{1}$ in tumours was measured on day 0 and at the endpoint day 7 ( $n=8$ per group). In some mice, $T_{1}$ could not always be determined and thus there were only $n=6$ or 7 per group for analysis. Results show the $\Delta T$ Vol (left panel) and the $\Delta T_{1}$ (right panel) for each treatment on day 7 where ${ }^{* *} p<0.001$ as shown. The ROC plots 1-specificity versus sensitivity for tumours treated with different doses of patupilone and has an AUC = 0.97; the dashed line is the line of equivalence where the $\mathrm{AUC}=0.5$

(non-significant increase of $20 \%$ ), this analysis showed that cell density and the extracellular space were unaffected. Many previous experiments in vitro and using human tumour xenografts in vivo have shown that $\mathrm{T}_{1}$ is sensitive to a) the amount of water in the extracellular space (but not intracellular) and b) the amount of protein in the water [21-25]. It is well recognised that inhibition of mTOR (the molecular target of everolimus) causes a decrease in cell size [26], because cell cycle progression is blocked at G1 thus inhibiting protein synthesis and cell growth. Consequently, cell density might not change, but the extracellular space could increase. Unfortunately we could not measure the average cell size because defining where one cell ends and another begins is difficult and there was no automatic programme for such an approach. But in any case, an increase in extracellular space would lead to an increase rather than a decrease in $\mathrm{T}_{1}$ [21-25], suggesting that if cell size changes occurred they could not explain the $T_{1}$ decrease that we have always observed following successful chemotherapy with many different agents [7]. This suggests to us, that tumour cell and vascular destruction leads to the release of proteins and also paramagnetic ions into the extracellular space which causes the decrease in $\mathrm{T}_{1}$; an effect which has been shown in vitro [22]. However, everolimus did not cause a decrease in the blood vessel density, as has been seen in several other tumour models [20,27-29], although this does not rule out an effect on the functional vasculature (previously measured as low in RIF-1 tumours [30]) and/or that early vascular changes had normalised by day 5. Also in this model, there was no clear evidence of increased tumour cell kill since caspase-3 levels were unaffected, although there did appear to be a strong trend for an increase in the PUFAs of everolimus-treated tumours which has been associated with apoptosis in other experimental models [10].

Immunohistochemistry (IHC) showed that approx. half of vehicle-treated RIF-1 tumour cells were positive for the nuclear antigen Ki67. Ki67 is considered to be a proliferation marker since it is expressed in all cycling cells (G1, S and G2M) but not therefore in cells in G0, and is a convenient IHC tool in the clinic for assessing tumour growth and response [31,32]. Given that the effect of mTOR inhibition is to block G1, it was not surprising that everolimus caused a marked decrease in the $\% \mathrm{Ki} 67^{+}$cells whether expressed as total number or density and there was a proportional increase in the cells negative for Ki67. Everolimus also decreased levels of total choline (Cho) in RIF-1 tumours, which is another marker of viable and proliferating cells, in this case reflecting membrane turnover. Cho tends to be higher in tumour than normal tissue [33] and successful chemotherapy has also been shown to decrease in Cho in both experimental models $[7,8,10]$ and the clinic $[34,35]$. In the RIF-1 tumours, these proliferation markers correlated significantly with each other as well as with the $\Delta T_{1}$, supporting the notion that $\Delta \mathrm{T}_{1}$ is a surrogate of the remaining number of proliferating cells in a tumour after therapy even though our histological analysis suggests that it cannot be measuring cell number or density directly. Support for this hypothesis came from the B16/ BL6 model treated with everolimus where again the

Table $2 T_{1}$ sensitivity and specificity tables for changes in RIF-1 tumour volume following everolimus or patupilone treatment

\begin{tabular}{lccc}
\hline A. Everolimus: using a $\Delta \mathrm{T}_{1}$ of $-8 \%$ & \multicolumn{2}{c}{$\Delta \mathrm{TVol}$} \\
\cline { 2 - 4 }$\Delta \mathrm{T}_{1}$ & Positive & Negative & Total \\
\hline Positive & $\mathbf{5}$ & $\mathbf{3}$ & $\mathbf{8}$ \\
Negative & 0 & 5 & 5 \\
Total & $\mathbf{5}$ & $\mathbf{8}$ & 13
\end{tabular}

B. Patupilone: using a $\Delta T_{1}$ of $-8 \%$.

\begin{tabular}{lccc} 
& \multicolumn{2}{c}{$\Delta \mathrm{TVol}$} & \\
\cline { 2 - 4 }$\Delta \mathrm{T}_{1}$ & Positive & Negative & Total \\
\hline Positive & 7 & 3 & 10 \\
Negative & 0 & 10 & 10 \\
Total & 7 & 13 & 20
\end{tabular}

A. Everolimus: The prevalence (total positive/all) $=0.38$. The sensitivity $=1.0$ and the 1 - specificity $=0.38$, giving a positive prediction value of 0.63 and a negative prediction value of 1.0 at this $\Delta \mathrm{T}_{1}$ cut-off of $-8 \%$.

B. Patupilone: The prevalence (total positive/all) $=0.35$. The sensitivity $=1.0$ and the 1 - specificity $=0.23$, giving a positive prediction value of 0.70 and a negative prediction value of 1.0 at this $\Delta \mathrm{T}_{1}$ cut-off of $-8 \%$. 


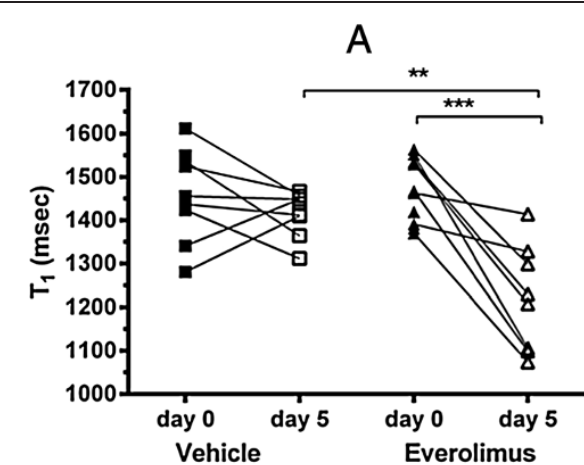

C

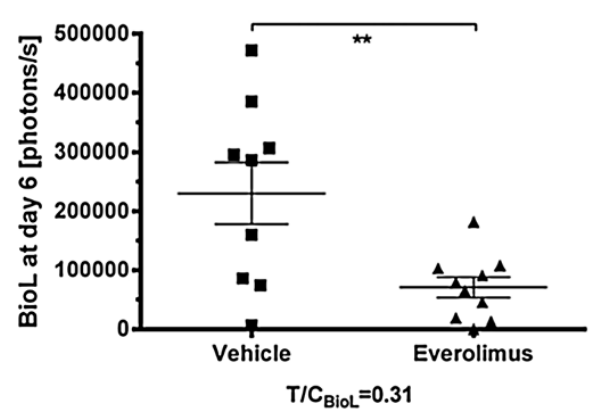

B

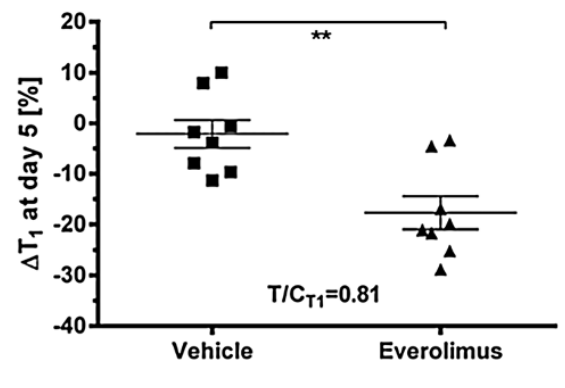

D

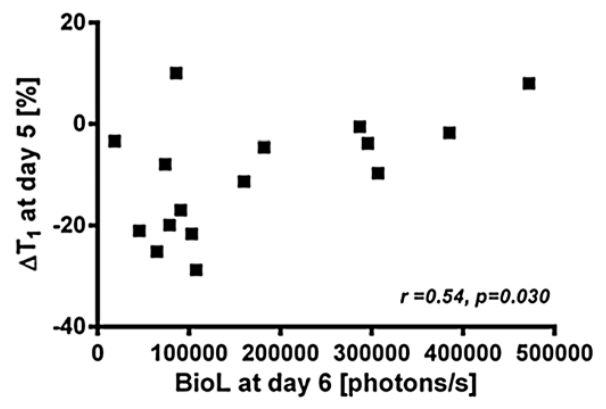

Figure 6 Everolimus decreases the $T_{1}$ and bioluminescence of cervical B16/BL6 melanoma metastases. C57/BL6 mice bearing B16/BL6 melanomas were treated with everolimus (10 mg/kg/day) or vehicle for 6 days and the spin-lattice relaxation of protons $\left(\mathrm{T}_{1}\right)$ in tumours was measured on day 0 and at the endpoint day 6. Lymph-nodes were removed and extracted for measurement of bioluminescence (BioL) as described in Methods. Results show the mean $\pm S E M$, and the individual $T_{1}$ values $(\mathbf{A})$ and bioluminescence $(\mathbf{C})$, the fractional change in $T_{1}\left(\Delta T_{1}\right)$ for the treatments $(\mathbf{B})$, and the Pearson correlations (with the associated $r$ and $p$ values) between BioL and $\Delta T_{1}$ (D), where ${ }^{* *} p<0.01$, ${ }^{* * *} p<0.001$ as shown.

decrease in bioluminescence, which measures viable tumour cell number, was correlated to the $\Delta \mathrm{T}_{1}$.

It is worth repeating that we have found that six different types of chemotherapy including anti-metabolites, inhibitors of mTOR, microtubules, VEGF-R, PI3K and HSP90 [7] [and unpublished] in several different tumourtypes implanted in both mouse and rat hosts, all showed a decrease in $T_{1}$ in response to successful chemotherapy i.e. characterized by a significant change in TVol in comparison to vehicle-treated tumours. Furthermore, where a tumour was resistant to that particular type of chemotherapy (paclitaxel and patupilone), there was no change in $\mathrm{T}_{1}$ [7]. This suggests that $\Delta T_{1}$ is a generic marker of tumour response, because, as discussed above, it reflects overall tumour destruction. But, what is the level of sensitivity and specificity i.e. how useful could such a method be in the clinic? To answer this question, we used receiveroperating-characteristic curves (ROC) to analyse two different models in which mice bearing RIF-1 tumours were treated with either a single dose of everolimus or three different doses of patupilone. In both cases, the ROCs had a large area-under-the-curve (AUC) of 0.84 and 0.97 which is considered of very good to outstanding predictive ability [17]. Consider for comparison, IHC markers of the mTOR pathway to predict everolimus activity in vitro using cell lines in which ROC-AUCs of 0.86-0.88 were determined
[20]; also excellent predictive activity but no better or even lower than that we have shown here. Indeed, with our data, if a cut-off of an $8 \%$ decrease were selected (i.e. $\Delta \mathrm{T}_{1}=-8 \%$ ), then the sensitivity to both drugs would be perfect in this model at 1.0 i.e. providing a negative predictive value of $100 \%$. In other words, after two MRIscans one could completely eliminate from the study any tumours with a $\mathrm{T}_{1}$ decrease smaller than $8 \%$ since these should not benefit from further treatment.

\section{Conclusion}

$\mathrm{T}_{1}$ showed a decrease in response to successful chemotherapy in several tumour models using various drugs. Analysis of histological and bioluminescence data from tumours treated with everolimus indicate that $\Delta \mathrm{T}_{1}$ is a generic marker of tumour response reflecting overall tumour destruction and the decreased number of proliferating cells.

The excellent negative predictive value of $\Delta T_{1}$ suggests that the method should be tested in the clinic, for example wherever MRI is being used anyway to determine tumour size. Potentially, it provides the opportunity to stratify a patient population after the first cycle of treatment to increase the effective response-rate as well as to save resources by avoiding treatment of patients who are unlikely to respond. 


\section{Abbreviations}

AUC: Area under curve; BioL: Bioluminescence; BV: Blood vessel; BW: Body weight; Cho: Total choline; $\Delta C h \circ / \mathrm{H}_{2} \mathrm{O}$ : Change in ratio total choline to unsuppressed water; IR True FISP: Inversion recovery true fast imaging with steady state precession sequence; MoA: Mechanism of action; MRI: Magnetic resonance imaging; MRS: Magnetic resonance spectroscopy; IHC: Immunohistochemistry; PRESS: Point resolved spectroscopy; PUFA: Polyunsaturated fatty-acids; ROC: Receiver operating characteristic curve; ROI: Region of interest; $T_{1}$ : Spin-lattice MR relaxation time; $\Delta T_{1}$ : Change in the spin-lattice relaxation time of water protons; $\Delta T$ Tol: Change in tumour volume; T/C: Treated-value divided by control-value.

\section{Competing interests}

All the authors are or were (CW) employees of Novartis Pharma AG, Basel, Switzerland. They declare no competing interests.

\section{Authors' contributions}

CW carried out the MRI and MRS studies, performed data and statistical analysis, and drafted the manuscript. PA carried out the MRI studies and critically revised the manuscript. MS performed and analysed histological and IHC studies. VR performed IHC studies and prepared figures with IHC data. SF took care of the animal model, the animal treatment, and carried out bioluminescence assessments. PM took care of the study design and coordination, performed data and statistical analysis, and drafted the manuscript. All authors read and approved the final manuscript.

\section{Acknowledgements}

We thank Caroline Fux and Mike Becquet for their excellent technical assistance, and Bettina Linssen and Barbara Zenger-Landolt from Definiens AG for helping with the Ki67 quantification.

The article processing charge was funded by the German Research Foundation (DFG) and the Albert Ludwigs University Freiburg in the funding programme Open Access Publishing.

\section{Author details}

'Oncology Research, Novartis Institutes for Biomedical Research, Basel, Switzerland. ${ }^{2}$ Global Imaging Group, Novartis Institutes for Biomedical Research, Basel, Switzerland. ${ }^{3}$ Department of Radiology Medical Physics, University Medical Center Freiburg, Magnetic Resonance Development and Application Center, Breisacher Str. 60a, 79106 Freiburg, Germany.

Received: 14 August 2013 Accepted: 11 February 2014 Published: 14 February 2014

\section{References}

1. Stephen RM, Gillies RJ: Promise and progress for functional and molecular imaging of response to targeted therapies. Pharm Res 2007, 24(6):1172-1185.

2. Mankoff DA, Eary JF, Link JM, Muzi M, Rajendran JG, Spence AM, Krohn KA: Tumor-specific positron emission tomography imaging in patients: [18 F] fluorodeoxyglucose and beyond. Clin Cancer Res 2007, 13(12):3460-3469.

3. Ferretti S, Allegrini PR, O'Reilly T, Schnell C, Stumm M, Wartmann M, Wood J, McSheehy PM: Patupilone induced vascular disruption in orthotopic rodent tumor models detected by magnetic resonance imaging and interstitial fluid pressure. Clin Cancer Res 2005, 11(21):7773-7784.

4. Ferretti S, Allegrini PR, Becquet MM, McSheehy PM: Tumor interstitial fluid pressure as an early-response marker for anticancer therapeutics. Neoplasia 2009, 11(9):874-881.

5. McSheehy P, Allegrini P, Ametaby S, Becquet M, Ebenhan T, Honer M, Ferretti S, Lane H, Schubiger P, Schnell C, et al: Minimally invasive biomarkers for therapy monitoring. Ernst Schering Found Symp Proc 2007, 4:153-188.

6. Honer M, Ebenhan T, Allegrini PR, Ametamey SM, Becquet M, Cannet C, Lane HA, O'Reilly TM, Schubiger PA, Sticker-Jantscheff M, et al: Anti-Angiogenic/Vascular Effects of the mTOR Inhibitor Everolimus Are Not Detectable by FDG/FLT-PET. Transl Oncol 2010, 3(4):264-275.

7. McSheehy P, Weidensteiner C, Cannet C, Ferretti S, Laurent D, Ruetz S, Stumm M, Allegrini P: Quantified tumor T1 is a generic early-response imaging biomarker for chemotherapy reflecting cell viability. Clin Cancer Res 2010, 16(1):212-225.

8. Jamin $Y$, Tucker ER, Poon E, Popov S, Vaughan L, Boult JK, Webber $H$, Hallsworth A, Baker LC, Jones C, et al: Evaluation of clinically translatable MR imaging biomarkers of therapeutic response in the
TH-MYCN transgenic mouse model of neuroblastoma. Radiology 2013, 266:130-140.

9. O'Connor JP, Carano RA, Clamp AR, Ross J, Ho CC, Jackson A, Parker GJ, Rose CJ, Peale FV, Friesenhahn M, et al: Quantifying antivascular effects of monoclonal antibodies to vascular endothelial growth factor: insights from imaging. Clin Cancer Res 2009, 15(21):6674-6682.

10. Hakumaki JM, Poptani H, Sandmair AM, Yla-Herttuala S, Kauppinen RA: 1H MRS detects polyunsaturated fatty acid accumulation during gene therapy of glioma: implications for the in vivo detection of apoptosis. Nat Med 1999, 5(11):1323-1327.

11. Lebwohl D, Anak O, Sahmoud T, Klimovsky J, Elmroth I, Haas T, Posluszny J, Saletan S, Berg W: Development of everolimus, a novel oral mTOR inhibitor, across a spectrum of diseases. Ann N Y Acad Sci 2013, 1291:14-32.

12. Ebenhan T, Honer M, Ametamey SM, Schubiger PA, Becquet M, Ferretti S, Cannet C, Rausch M, McSheehy PM: Comparison of [18 F]-tracers in various experimental tumor models by PET imaging and identification of an early response biomarker for the novel microtubule stabilizer patupilone. Mol Imaging Biol 2009, 11(5):308-321.

13. O'Reilly T, Lane HA, Wood JM, Schnell C, Littlewood-Evans A, Brueggen J, McSheehy PM: Everolimus and PTK/ZK show synergistic growth inhibition in the orthotopic BL16/BL6 murine melanoma model. Cancer Chemother Pharmacol 2011, 67(1):193-200.

14. Scheffler K, Hennig J: T1 quantification with inversion recovery TrueFISP. Magn Reson Med 2001, 45(4):720-723.

15. Schmitt P, Griswold MA, Jakob PM, Kotas M, Gulani V, Flentje M, Haase A: Inversion recovery TrueFISP: quantification of $\mathrm{T}(1), \mathrm{T}(2)$, and spin density. Magn Reson Med 2004, 51(4):661-667.

16. Wu J: Statistical inference for tumor growth inhibition $\mathrm{T} / \mathrm{C}$ ratio J Biopharm Stat 2010, 20(5):954-964.

17. Lehr RG, Pong A: ROC curve. In Encyclopedia of Biopharmaceutical Statistics. New York: Marcel Dekker; 2003:884-891.

18. Fardy JM: Evaluation of diagnostic tests. Methods Mol Biol 2009, 473:127-136.

19. Lane HA, Wood JM, McSheehy PM, Allegrini PR, Boulay A, Brueggen J, Littlewood-Evans A, Maira SM, Martiny-Baron G, Schnell CR, et al: mTOR inhibitor RAD001 (everolimus) has antiangiogenic/vascular properties distinct from a VEGFR tyrosine kinase inhibitor. Clin Cancer Res 2009, 15(5):1612-1622.

20. O'Reilly T, MCSheehy PM: Biomarker development for the clinical activity of the mTOR inhibitor everolimus (RAD001): processes, limitations, and further proposals. Transl Oncol 2010, 3(2):65-79.

21. Braunschweiger $P G$, Schiffer L, Furmanski P: The measurement of extracellular water volumes in tissues by gadolinium modification of ${ }^{1}$ H NMR spin lattice (T1) relaxation. Magn Reson Imaging 1986, 4(4):285-291.

22. Braunschweiger $P G$, Schiffer $L$, Furmanski P: $1 H-N M R$ relaxation times and water compartmentalization in experimental tumor models. Magn Reson Imaging 1986, 4(4):335-342.

23. Rofstad EK, Steinsland E, Kaalhus O, Chang YB, Hovik B, Lyng H: Magnetic resonance imaging of human melanoma xenografts in vivo: proton spin-lattice and spin-spin relaxation times versus fractional tumour water content and fraction of necrotic tumour tissue. Int J Radiat Biol 1994, 65(3):387-401.

24. Jakobsen I, Kaalhus O, Lyng H, Rofstad EK: Detection of necrosis in human tumour xenografts by proton magnetic resonance imaging. $\mathrm{Br} J \mathrm{Cancer}$ 1995, 71(3):456-461.

25. Jakobsen I, Lyng H, Kaalhus O, Rofstad EK: MRI of human tumor xenografts in vivo: proton relaxation times and extracellular tumor volume. Magn Reson Imaging 1995, 13(5):693-700.

26. Fingar DC, Blenis J: Target of rapamycin (TOR): an integrator of nutrient and growth factor signals and coordinator of cell growth and cell cycle progression. Oncogene 2004, 23(18):3151-3171.

27. Mabuchi S, Altomare DA, Connolly DC, Klein-Szanto A, Litwin S, Hoelzle MK, Hensley HH, Hamilton TC, Testa JR: RAD001 (Everolimus) delays tumor onset and progression in a transgenic mouse model of ovarian cancer. Cancer Res 2007, 67(6):2408-2413.

28. Manegold PC, Paringer C, Kulka U, Krimmel K, Eichhorn ME, Wilkowski R, Jauch KW, Guba M, Bruns CJ: Antiangiogenic therapy with mammalian target of rapamycin inhibitor RAD001 (Everolimus) increases radiosensitivity in solid cancer. Clin Cancer Res 2008, 14(3):892-900.

29. Shinohara ET, Cao C, Niermann K, Mu Y, Zeng F, Hallahan DE, Lu B: Enhanced radiation damage of tumor vasculature by mTOR inhibitors. Oncogene 2005, 24(35):5414-5422. 
30. Robinson SP, Rijken PF, Howe FA, McSheehy PM, van der Sanden BP, Heerschap A, Stubbs M, van der Kogel AJ, Griffiths JR: Tumor vascular architecture and function evaluated by non-invasive susceptibility MRI methods and immunohistochemistry. J Magn Reson Imaging 2003, 17(4):445-454

31. Landberg G, Tan EM, Roos G: Flow cytometric multiparameter analysis of proliferating cell nuclear antigen/cyclin and Ki-67 antigen: a new view of the cell cycle. Exp Cell Res 1990, 187(1):111-118.

32. Beresford MJ, Wilson GD, Makris A: Measuring proliferation in breast cancer: practicalities and applications. Breast Cancer Res 2006, 8(6):216.

33. Katz-Brull R, Lavin PT, Lenkinski RE: Clinical utility of proton magnetic resonance spectroscopy in characterizing breast lesions. J Natl Cancer Inst 2002, 94(16):1197-1203.

34. Meisamy S, Bolan PJ, Baker EH, Bliss RL, Gulbahce E, Everson LI, Nelson MT, Emory TH, Tuttle TM, Yee D, et al: Neoadjuvant chemotherapy of locally advanced breast cancer: predicting response with in vivo (1)H MR spectroscopy-a pilot study at 4 T. Radiology 2004, 233(2):424-431.

35. Tozaki M, Oyama Y, Fukuma E: Preliminary study of early response to neoadjuvant chemotherapy after the first cycle in breast cancer: comparison of $1 \mathrm{H}$ magnetic resonance spectroscopy with diffusion magnetic resonance imaging. Jpn J Radiol 2010, 28(2):101-109.

doi:10.1186/1471-2407-14-88

Cite this article as: Weidensteiner et al.: Tumour $\mathrm{T}_{1}$ changes in vivo are highly predictive of response to chemotherapy and reflect the number of viable tumour cells - a preclinical MR study in mice. BMC Cancer 2014 14:88.

\section{Submit your next manuscript to BioMed Central and take full advantage of:}

- Convenient online submission

- Thorough peer review

- No space constraints or color figure charges

- Immediate publication on acceptance

- Inclusion in PubMed, CAS, Scopus and Google Scholar

- Research which is freely available for redistribution 